Case Report

\title{
PROSTHODONTIC REHABILITATION OF A PATIENT WITH HOLLOW BULB OBTURATOR : A CASE REPORT
}

\author{
Harshitha Alva ${ }^{1}$, Krishna Prasad D. ${ }^{2}$, Anupama Prasad D. ${ }^{3}$ \\ ${ }^{1}$ P.G. Student, ${ }^{2}$ Professor and H.O.D., ${ }^{3}$ Lecturer \\ Department of Prosthodontics and Crown \& Bridge, A.B. Shetty M emorial Institute of Dental Sciences, \\ Nitte University, Deralakatte , M angalore - 575018 \\ Correspondence : \\ Krishna Prasad D. \\ Professor and Head of the Department, Department of Prosthodontics \\ A.B. Shetty M emorial Institute of Dental Sciences, Nitte University, Deralakatte , M angalore - 575018 \\ E-mail: drkrishnaprasadd@yahoo.in
}

\begin{abstract}
:
A prosthesis used to close a palatal defect in dentulous or partially edentulous mouth is correctly referred to as an obturator. An obturator serves to restore speech, mastication, deglutition and esthetics. A light weight hollow obturator optimises retention and stability as well as patient comfort.

This case report describes the fabrication of an hollow bulb obturator for a completely edentulous patient who has undergone wide excision and partial alveolar resection squeal of management of pleomorphic adenoma of the palate.
\end{abstract}

Keywords: wide excision, pleomorphic adenoma, hollow bulb

\section{Introduction:}

An obturator is designed for patients after maxillectomy as a part of management of neoplasms of antral and /or ethmoidal sinuses ${ }^{1}$. It is defined as prosthesis used to close a congenital or an acquired opening in the palate 2 .

When the defect is large, restoration of speech, mastication, deglutition, and esthetics are important concerns ${ }^{3}$. Light weight, cleanliness and simplicity are important considerations in the fabrication of a prosthesis to obdurate the defect after a maxillary resection. Since the weight of an obturator is often the most common reason to dislodge a denture, it should be as light as possible 4 . Reduction in weight of the obturator is attained by hallowing the prosthesis. A light weight hollow obturator optimises retention and stability as well as patient comfort.

Hollow obturators can be either open or closed. A closed obturator is found to prevent percolation of fluid and reduce air space in the defect. There are numerous controversies regarding the fabrication of open and closed hollow obturators.

This case report describes the use of condensation silicone during processing in the fabrication of an hallow obturator and thereby enhancing the retention and speech.

\section{Case report:}

A 56year old completely edentulous female patient reported with a chief complaint of mass in the oral cavity since 15years which was diagnosed as Pleomorphic adenoma of the hard palate. Wide excision and partial alveolar resection was carried out under general anaesthesia(fig 1). One week after surgery an impression of the maxillary arch with the defect was made with irreversible hydrocolloid impression material (Zelgan plus Dentsply). The impression was poured with dental stone (type III) and a delayed surgical obturator was fabricated on it using acrylic resin (DPI-heat cure)(Fig 2). Definitive obturation was done 3 months post-surgically with a bilaterally balanced complete denture prosthesis along with a hollow bulb extending into the defect.

After 3 months maxillary and mandibular diagnostic impressions were made again with irreversible hydrocolloid impression material (Zelgan plus- Dentsply) and casts were poured with dental stone (Type-III). Special trays were fabricated on these casts using acrylic resin (DPIcold cure) and secondary impressions were made. Putty and light viscosity vinyl polysiloxane impression material (3M ESPE, Express, U.S.A.) was used for secondary impression. The defect was recorded using irreversible 
hydrocolloid impression material (Neocolloid) (Fig 3)and the master cast was obtained. Base plate and occlusal rims were fabricated on the casts. Jaw relations along with face bow transfer were recorded and transferred to a NonArcon semi adjustable articulator. Teeth arrangement was carried out to attain a tentative bilateral balanced occlusion and centric relation was recorded using alu wax to verify the pre-determined centric position and a protrusive record was also made at $6 \mathrm{~mm}$ protrusion. This protrusive record was then used to determine the condylar guidance. A condylar guidance of $30^{\circ}$ on right and $35^{\circ}$ on left side was obtained. The lateral guidance for each side was calculated using Hanau's formula and was found to be $16^{\circ}$ and $18^{\circ}$ for right and left side respectively. Using these values the tentative arrangement of teeth and their angulations were altered to attain a proper bilateral balanced occlusion. Dentures were processed after try-in of the waxed up dentures.

After dewaxing, to fabricate a hollow obturator an initial mix of acrylic resin is placed only on the defect area of about 2-4mm thickness. Over this putty vinyl polysiloxane impression material is manipulated and adapted with gentle pressure and contoured to the shape of palate. Now the denture is packed following the routine procedure. Denture stains were added during packing so as to charecterise the denture for better esthetics. After deflasking, a hole is drilled on the bulb surface and the putty isteased out to make the obturator hollow (fig 4). The hole is then resealed using acrylic resin (DPI-cold cure). The denture was trimmed, polished and fit and insertion done. During denture fit-in, care should be taken that there are no rough borders that can traumatise the tissues and patient should be trained adequately for easy insertion and removal of the prosthesis(fig 5,6).

\section{Discussion:}

Rehabilitation of patients who have undergone eradication of neoplasm of the maxillae requires restoration of mastication, speech and deglutition. Ability to reduce the weight of the prosthesis by hollowing the obturator is found to be beneficial ${ }^{3}$. Several techniques have been advocated in the fabrication of hollow obturators. There even exist controversies regarding closed and open hollow obturators. The closed obturator is found to prevent percolation of fluid and decrease air space in the defect, however it is also found that fluids can be absorbed through the porosities in the acrylic resin seal and in such situations, patients are unable to clean the inner surface of the closed system. This unhygienic situation harbours the growth of microorganisms.

The material used in the fabrication of obturators should be biocompatible, impermeable, smooth and easily made. Numerous studies have been put forth in the literature for the fabrication of hollow obturator using variety of materials. Hollow obturators are made with acrylic resin in either open or closed configuration ${ }^{5,6,7,8}$. However silicone either solely or in combination with other materials has also been used for this purpose 9 . Controlling the thickness of hollow obturator walls is important to provide adequate strength and weight of the prosthesis. Materials such as ice $^{10}$ and sugar ${ }^{11}$ have been used in the defect portion during processing and then removed through holes after processing.

This case report describes the fabrication of a hollow bulb obturator using vinyl polysiloxane material to fill the defect. The added advantage of this technique is that since the materials hardens on setting, the contours are maintained whereas use of sugar tents to distort the shape as a result of the pressure applied during packing. Here the denture was fabricated with bilateral balanced occlusion. Bilateral balance help to seat the denture in a stable position during mastication, swallowing thereby enhancing the retention and stability of the denture and also the health of the oral tissues.

\section{Conclusion :}

The concept of rehabilitation of patients with large defects of the maxilla with hollow bulb obturators provides a means of enhancing the retention, mastication, deglutition, speech and esthetics in the post-operative period. A prosthesis so designed provides a functional solution to the compromised state of the patient. 
Figures:

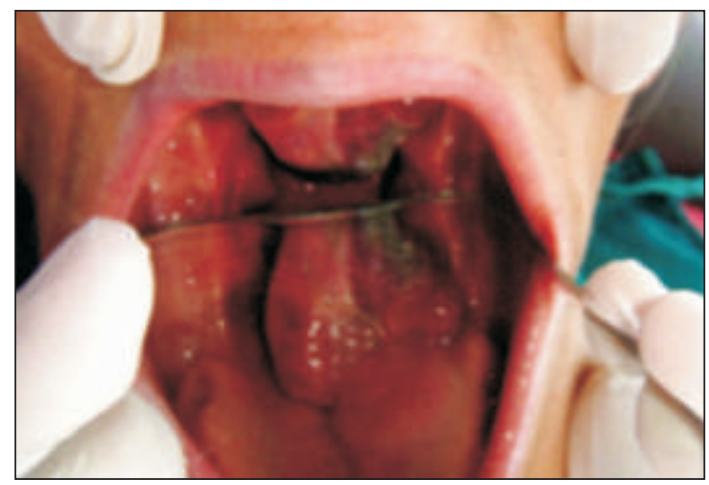

fig 1: pre-operative

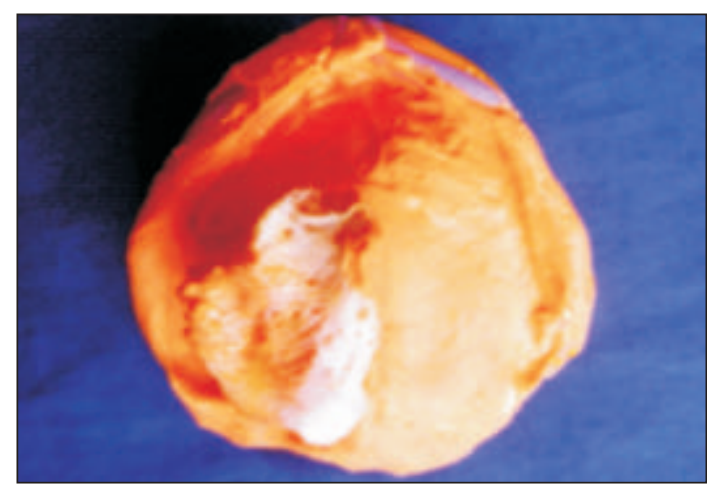

fig 3 : final impression

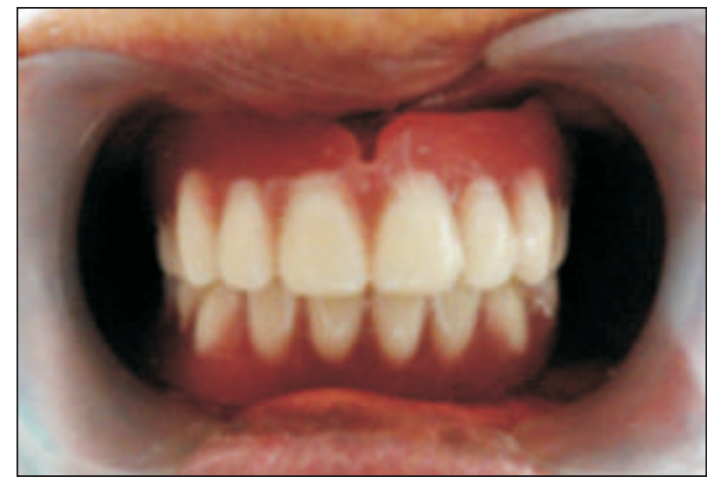

fig 5 : centric relation

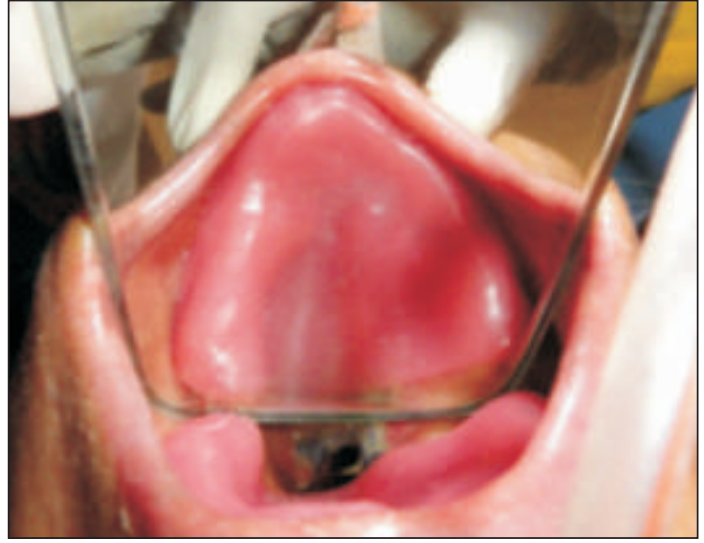

fig 2: delayed surgical obturator

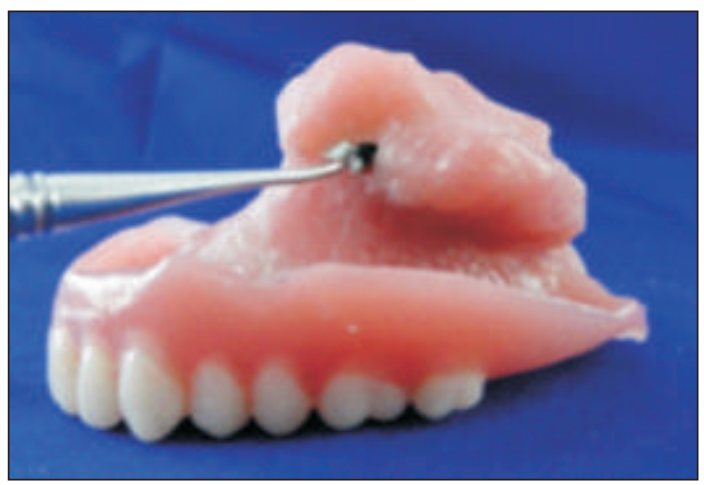

fig 4 : putty being teased out of the obturator to make it hollow in the definitive obturator

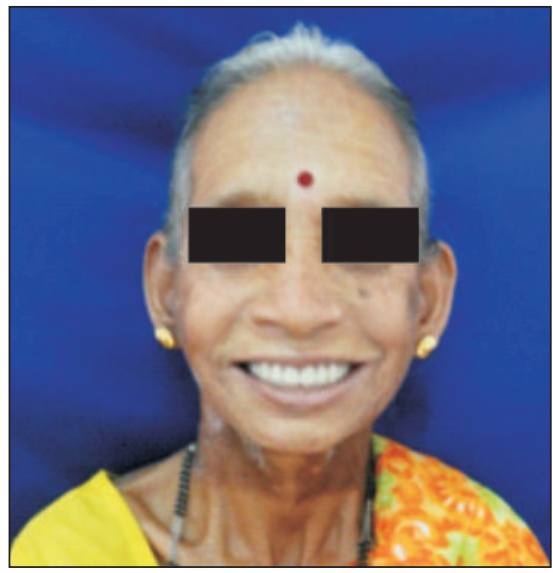

fig 6: post-operative

\section{References:}

1. Payne A G,Welton W G. An inflatable obturator for use following maxillectomy.J Prosthet Dent.1965 jul-aug;15:759-63.

2. Gay WD, King GE. Applying basic prosthodontic principles in the dentulous maxillectomy patient. J Prosthet Dent. 1980 Apr;43(4):433-5.

3. Phankosol P, Martin JW. Hollow obturator with removable lid. Prosthet Dent. 1985Jul; 54(1):98-100.

4. Chalian VA, Barnett M O. A new technique for constructing a one piece hollow obturator after partial maxillectomy. J Prosthet Dent. 1972 Oct; 28(4):448-53.

5. Worley JL, Kniejski ME. A method for controlling the thickness of hollow obturator prostheses. J Prosthet Dent. 1983 Aug; 50(2):227-9.

6. Browning JD, Kinderknecht J. Fabrication of a hollow obturator with fluid resin.J Prosthet Dent. 1984 Dec; 52(6):891-5.

7. Shifman A. A technique for the fabrication of the open obturator. J Prosthet Dent. 1983 Sep; 50(3):384-5.

8. Knapp JG. A simplified approach to the fabrication of a maxillary hollow obturator prosthesis. J Prosthet Dent. 1984 Jan; 51(1):67-9.

9. Taicher S, Rosen AG, Arbree NS, Bergen SF, Levy M, Lepley JB. A technique for the fabrication of polydimethylsiloxane acrylic resin obturators. J Prosthet Dent. 1983 Jul; 50(1):65-8.

10. Schneider A: Method of fabricating a hollow obturator. J Prosthet Dent. 1978 Sep; 40(3):351

11. Parel SM, LaFuente H. Single visit hollow obturator for edentulous patients. J Prosthet Dent.1978 Oct;40(4):426-9. 